\title{
Voces católicas y propaganda movilizadora ante la Ley de Confesiones y Congregaciones Religiosas
}

\author{
Adolfo Carratalá \\ Universitat de València \\ adolfo.carratala@uv.es
}

\begin{abstract}
Resumen:
La Ley de Confesiones y Congregaciones Religiosas, aprobada el 17 de mayo de 1933 por las Cortes de la II República española, prohibió que la Iglesia continuase ejerciendo la enseñanza. La medida despertó la indignación de diversos actores conservadores: políticos, obispos y líderes de organizaciones católicas. Su objetivo fue la derogación de la ley y, para ello, dedicaron grandes esfuerzos a activar la reacción de los católicos. Este artículo examina algunos de los mensajes propagandísticos difundidos durante aquellos meses para desvelar sus estrategias movilizadoras.
\end{abstract}

Palabras clave: II República; propaganda; movilización; educación; organizaciones católicas.

\section{Catholic voices and mobilizing propaganda facing the Religious Confes- sions and Congregations Law}

\begin{abstract}
:
The Religious Confessions and Congregations Law, adopted on May 17, 1933 by the Parliament of the Second Spanish Republic, forbade Church to continue practicing teaching. The measure aroused the indignation of many conservative actors: politicians, bishops and leaders of Catholic organizations. Their objective was the repeal of the law and, for that, they all devoted great efforts to promote the reaction of Catholics. This paper examines some of the propaganda messages spread during those months to reveal their mobilizing strategies.
\end{abstract}

Key Words: Second Spanish Republic; propaganda; mobilization; education; Catholic organizations.

\section{Referencia normalizada:}

Carratalá, A. (2014): Voces católicas y propaganda movilizadora ante la Ley de Confesiones y Congregaciones Religiosas. Historia y Comunicación Social. Vol. 19. Núm. Especial Marzo. Págs. 289-299.

Sumario: 1. Introducción teórica. 1.1. La Ley de Confesiones y Congregaciones Religiosas. 1.2. El movimiento en contra de la norma: principales actores. 1.2.1. La oposición a la ley desde la tribuna parlamentaria. 1.2.2. La oposición a la ley desde los altares. 1.2.3. La oposición a la ley desde la calle. 1.3. La propaganda con sello católico. 2. Aproximación metodológica. 3. Resultados: los elementos propagandísticos del mensaje católico. 4. Conclusiones. 5. Referencias bibliográficas. 


\section{Introducción teórica}

\subsection{La ley de confesiones y congregaciones religiosas}

La idea de que la Iglesia española había funcionado como un freno para el progreso cultural del país se encontraba latente entre importantes sectores de la opinión pública antes de la llegada del régimen republicano. En ese contexto, la educación era contemplada como un asunto que no podía continuar por más tiempo bajo el control de la institución católica. Así, el carácter laico del sistema educativo se convirtió en una prioridad para los primeros gobiernos de la II República. La Ley de Confesiones y Congregaciones Religiosas, que desarrollaba el artículo $26^{\circ}$ de la Constitución, fue la norma más destacada de todas las que se adoptaron para avanzar en esa dirección. El Gobierno de Azaña y toda la izquierda pensaron que, con ella, se asentarían "los más sólidos cimientos para construir un Estado laico" (Verdoy, 2009: 356). En su título VI, se establecía la prohibición del ejercicio de la enseñanza a las órdenes y congregaciones religiosas:

Las Órdenes y Congregaciones religiosas no podrán dedicarse al ejercicio de la enseñanza. No se entenderán comprendidas en esta prohibición las enseñanzas que organice la formación de sus propios miembros. La inspección del Estado cuidará de que las Órdenes y Congregaciones religiosas no puedan crear o sostener colegios de enseñanza privada ni directamente ni valiéndose de personas seglares interpuestas.

La norma indicaba que las órdenes confesionales disponían de un año para cesar en actividades docentes y, a partir de ese momento, el Estado se encargaría de la enseñanza de todos los niños del país. Era el inicio de lo que algunos autores han denominado "el combate más duro de la «guerra escolar»" (Ostolaza, 2009: 335). $\mathrm{Ni}$ enmiendas ni votos particulares fueron aceptados a lo largo de los tres meses y medio durante los que se prolongó el debate. Finalmente, el texto fue aprobado el 17 de mayo de 1933 por 278 votos a favor y 50 en contra, de las fuerzas monárquicas y agrarias.

\subsection{El movimiento en contra de la norma: principales actores}

\subsubsection{La oposición a la ley desde la tribuna parlamentaria}

Las fuerzas políticas conservadoras se posicionaron firmemente en contra de la norma. Su oposición ya quedó fijada durante el debate sobre la Constitución en 1931, como demostró con claridad el diputado Gil Robles cuando acusó a los responsables del proyecto de concentrar en la prohibición recogida en el artículo $26^{\circ}$ sus deseos de persecución a la Iglesia: "el dictamen que se ha aprobado [...] es un principio netamente persecutorio que los católicos no aceptamos, que no podemos aceptar" (Meer, 1978: 161). El diputado se mantuvo fiel a su palabra y, ya en plena tramitación de la ley, mostró una idéntica actitud de rechazo. Como presidente en ese momento de Acción Popular, Gil Robles aseguró que haría "todo lo posible" y todo lo que estu- 
viera en su mano "para desobedecerla y para predicar su desobediencia individual y colectivamente" (Ramírez, 1969: 247).

Acción Popular era el nombre con el que era conocida la organización política que, hasta el 29 de abril de 1932, se denominó Acción Nacional, una formación derechista que intentó, desde sus inicios, articular la defensa de las clases conservadoras ante el régimen republicano empleando la confesionalidad como "símbolo de integración política" (Montero, 1977b: 92). Tras unos resultados pobres en las elecciones a Cortes Constituyentes, la organización afrontó una serie de cambios que comenzaron con la llegada de Gil Robles a la presidencia el 19 de octubre de 1931, bajo quien pasó de ser "una organización de elites a un partido de masas" (Grandío, 2008: 102). Dos años más tarde, fue también él quien se situó al frente de la Confederación Española de Derechas Autónomas (CEDA) de cara a las elecciones generales de 1933, una poderosa plataforma política que colocó las reivindicaciones de carácter religioso en el primer lugar de su programa, propaganda y acción.

\subsubsection{La oposición a la ley desde los altares}

La Ley de Confesiones y Congregaciones Religiosas también fue atacada por el episcopado. La declaración colectiva de 25 de mayo de 1933 la criticó abiertamente al denunciar "con un tono durísimo aunque respetuoso" el "laicismo agresivo" que había inspirado la Constitución (Álvarez, 2009: 70). El lenguaje empleado por los obispos resultó más agresivo que en ocasiones anteriores y sus llamadas a la comunidad católica para que participara en las reivindicaciones escolares de la Iglesia también se mostraban más apremiantes (Pérez, 1988: 140-141), aconsejando a los fieles "una actitud hostil, de lucha" (Ramírez, 1969: 217-218). De este modo, las recomendaciones a los devotos, entre las que estaba la prohibición severa de asistir a las escuelas acatólicas, neutras o mixtas, "se concretaban ahora en obligaciones terminantes" (Puelles, 2002: 279), "normas de obligado cumplimiento" para todos los católicos (Ostolaza, 2009: 336).

El comunicado sintonizó plenamente con la condena que el papa haría de la norma en su encíclica Dilectissima nobis, de 3 de junio, en la que, con "un tono de hostilidad inequívoca" (López, 2008: 162), Pío XI presentaba la ley como una ofensa a la Iglesia, se refería a ella como "obra de ingratitud y manifiesta injusticia que va contra la libertad" y pedía a los católicos que se unieran disciplinados en su contra. Según De Puelles, esta encíclica, que supuso el "momento álgido" de la "guerra escolar", fue "una declaración oficial de guerra" (2002: 280).

\subsubsection{La oposición a la ley desde la calle}

Los grupos de presión habían proliferado y desarrollaban una sugestiva labor de influencia desde 1931, aprovechando la válvula de escape y el terreno de acción abiertos por la República (Ramírez, 1969: 344) de modo que los católicos ya gozaban de una notable y eficaz organización cuando la Ley de Confesiones y Congregaciones Religiosas fue aprobada en las Cortes. La cruzada permitió organizar, activar y politi- 
zar redes sociales, movilizar a sus seguidores, buscar votos para ganar las elecciones, fundar decenas de asociaciones católicas nuevas e incorporar miles de individuos (jóvenes, mujeres, padres de familia, maestros y profesores...) a las ya existentes (Cruz, 2006: 56).

Herrera Oria fue una figura clave en el inicio y crecimiento de estos colectivos, pues estuvo al frente de la Asociación Católica Nacional de Propagandistas (ACN de P) y, más tarde, presidió la Junta Central de Acción Católica. La primera contemplaba entre sus principales objetivos "dar a los católicos mayor peso y organización en la vida social y en la vida política" (Ordovás, 1993: 20), para lo que preparó a católicos militantes para la organización de mítines y conferencias que difundieran la necesidad de la fe. La segunda, con Herrera como máximo responsable, trasladó los temas que ocupaban a la anterior a un plano masivo. Como protesta ante la Ley de Confesiones, Acción Católica organizó las Semanas Pro Ecclesia et Patria, que se celebraban en todas las diócesis y finalizaban con una manifestación religiosa y propagandística de masas de evidente carácter político (Montero, 2008: 32).

Junto a estas dos grandes organizaciones cabe subrayar el crucial papel que jugaron en aquellos años otros grupos específicamente vinculados a la escuela: la Federación de Amigos de la Enseñanza, la Agrupación Defensa y Libertad de los Padres en la Educación de los Hijos, las Ligas Contra la Pública Inmoralidad, la Confederación Católica Nacional de Padres de Familia... Destaca el protagonismo de esta última, una poderosa e influyente organización encargada de emprender una «cruzada» en defensa de, entre otras cuestiones, el monopolio eclesiástico de la enseñanza (López, 2009: 406). Su acción se intensificó sensiblemente en 1933, coincidiendo con la aprobación de la Ley de Confesiones. Según recoge Watanabe:

Para la CPPF las leyes anticatólicas sobre la educación aconfesional del primer bienio republicano equivalían a la vulneración de los derechos de los padres, a los que el Estado debía dejar libre la iniciativa en cuanto a la educación de sus hijos. La CPPF se dedicaba más a ejercer el derecho de protesta ante los poderes públicos y a difundir los ideales católicos por medio de la propaganda oral y escrita, dentro y, sobre todo, fuera de las parroquias (Watanabe, 2003: 291).

Con el apoyo de este tejido de organizaciones, el rechazo a la norma fue creciendo hasta ser compartido por un importante sector social, lanzando a muchos ciudadanos a la calle:

Con motivo de la protesta por la nueva ley, la movilización de los católicos alcanzó una cota altísima; no hubo día entre febrero y junio de 1933 que no se hiciera público un manifiesto o que no se produjera una manifestación en algún rincón del país (Álvarez, 2009: 68).

\subsection{La propaganda con sello católico}

Los portavoces de la derecha católica promovieron una lectura de los acontecimientos ocurridos a partir de 1931 basada en una lógica dicotómica que permitía deformar el modo como se contemplaban los hechos alentando el miedo entre los 
católicos. Se trató de una representación de la realidad social absolutamente polarizada con claros objetivos propagandísticos. Para poder llevar a cabo esa estrategia persuasiva, las diversas fuerzas católicas precisaron medios y soportes que permitieran difundir con éxito sus mensajes movilizadores. En los años estudiados, ese esfuerzo encontró múltiples canales de propagación, tanto en la prensa afín como en publicaciones propias.

La prensa ya hacía tiempo que se había convertido en una prioridad para la Iglesia española, como había demostrado la llamada 'buena prensa' surgida en España a finales del siglo XIX, y durante el Primer Bienio de la II República su protagonismo se potenció: la ACN de $\mathrm{P}$ encontró en El Debate la vía para hacer llegar a las masas su mensaje de defensa de la Iglesia, la CEDA disfrutó de la colaboración de cabeceras como Hoy, Ideal, Diario de Valencia, La Gaceta del Norte o Ya para la tarea de modelar la opinión pública y Acción Católica también dispuso de "un número importante de publicaciones periódicas, que en total sumaba una significativa cifra de tirada" como ayuda clave para desarrollar su labor (Sánchez, 2005: 93).

Asimismo, las organizaciones políticas y sociales pusieron en marcha múltiples iniciativas para propagar sus agitadores mensajes. La ACN de P contó con la Editorial Católica, que publicó muchos libros y folletos propagandísticos (Watanabe, 2003: 29) y con un boletín interno. La Sección de Propaganda de la Juventud de Acción Popular organizó mítines y conferencias por las principales capitales de provincia y difundió artículos y folletos (Montero, 1977a: 617-620). La CEDA, ante las elecciones de 1933, además de contar con órganos oficiales y simpatizantes, dio un protagonismo clave a su labor propagandística y hizo uso de todo tipo de medios: pasquines, carteles, mítines, la aviación, la radio y la actividad de los grupos de presión (Montero, 1977b: 299). La Confederación Católica Nacional de Padres de Familia disponía de un boletín mensual como órgano de expresión y de la revista Hogar. Por su lado, la Federación de Amigos de la Enseñanza se volcó en el trabajo de persuasión, convocando, por ejemplo, cursos de formación de propagandistas.

\section{Aproximación metodológica}

El análisis de los mensajes propagandísticos difundidos por diferentes actores católicos contra la Ley de Confesiones y Congregaciones Religiosas durante 1932 y 1933 se lleva a cabo desde una aproximación cualitativa. Dado que entendemos que estos discursos buscaban activar la movilización de los ciudadanos, presuponemos que la articulación de sus mensajes de denuncia descansa sobre un marco que subraya, por encima de cualquier otro aspecto, la comisión de una injusticia. Partiendo de la propuesta de marco de acción colectiva investigada por William Gamson, examinamos diferentes muestras de propaganda discursiva para identificar qué formas adquiere ese elemento de injusticia, así como los componentes de identidad y agencia que complementan el encuadre movilizador. Para ello, empleamos la 
prensa del momento, en concreto $A B C$ y $E l$ Debate, asumiendo que ambas publicaciones actuaron como sponsors de frames (Gamson, 1984: 80).

Los resultados obtenidos del estudio aparecen expuestos de tal manera que, en primer lugar, comentamos los discursos elaborados y difundidos por actores políticos, seguidamente los firmados por miembros de la jerarquía eclesiástica $\mathrm{y}$, por último, los producidos por individuos vinculados con las organizaciones de perfil católico descritas anteriormente. En la explicación de los elementos identificados como componentes de los marcos de acción colectiva, hemos optado por emplear la cursiva para resaltar los que se corresponderían con la injusticia, el subrayado para indicar cuáles sugieren la identidad y la cursiva junto con el subrayado para poner de relieve cuáles son las expresiones en las que detectamos el componente de agencia.

\section{Resultados: los elementos propagandísticos del mensaje católico}

Los políticos más conservadores destacaron por dirigirse con frecuencia a los católicos para advertirles de los peligros que, en su opinión, entrañaba la obra legislativa aprobada por los primeros Ejecutivos de la República. Gil Robles estuvo al frente de muchos de estos esfuerzos y, por ello, son de él gran parte de los mensajes que la prensa recogió con este fin. Durante los debates parlamentarios que acompañaron la tramitación de la Ley de Confesiones y Congregaciones Religiosas, el diputado conservador tomó la palabra para, por un lado, poner de manifiesto la injusticia que él consideraba que pretendía acometerse con la puesta en marcha de la norma:

...ésta es una ley totalmente antisocial, es una ley que va fundamentalmente contra ese derecho de los padres, más bien contra esa sagrada obligación de los padres, que yo más de una vez he procurado definir aquí, de buscar para sus hijos aquellos maestros que tengan por conveniente, sin limitación alguna por parte del Estado (El Debate, 10/02/1933).

Por otro, delimita claramente la existencia de dos polos bien diferenciados en el conflicto. Así, Gil Robles estaría identificándose con el pueblo español, católico, frente a una minoría agresiva:

...cuando habláis de cordialidad con los elementos de derecha, olvidáis que esta nueva agresión, totalmente injustificada, como todas, parte exclusivamente de voso$\underline{\text { tros, }}$ que sois los que desencadenáis una guerra espiritual entre los españoles, que abrís un abismo, que no se llenará mientras esa ley esté en vigor, y que nosotros, las fuerzas de derecha, que hoy somos escasos aquí dentro, pero que seremos muchos el día que vosotros no estéis atornillados ahí con un verdadero contrato bilateral con el Gobierno, impondremos la ley, porque ese día vendremos aquí con la razón y con la justicia y no toleraremos que se imponga una ley de excepción por el mero hecho de ser católicos (El Debate, 10/02/1933).

La protesta salió del Parlamento y continuó en la calle, donde el objetivo ya no fue tanto afear a los socialistas su actitud al sacar adelante la ley sino insuflar ánimo y 
exhortar a los católicos para que éstos mostraran su rechazo más absoluto a la norma. Uno de los eventos principales se llevó a cabo en el cine de la Ópera en febrero de 1933, donde, de nuevo, Gil Robles denunció la norma por considerarla opuesta a los derechos de los católicos, a quienes pidió actuar:

En un terreno humano tenemos que atacar esa ley, por antiespañola, confeccionada por estos ensayistas que desgobiernan a España.

Con mi exclusiva responsabilidad digo que a ese funesto proyecto hay que declararle hostilidad implacable. Lo combatiremos a sangre y fuego $(A B C, 21 / 02 / 1933)$.

Y si esa ley llega a estar vigente, tenemos que desobedecerla... (El Debate, 21/02/1933).

Los obispos también tuvieron un papel muy destacado en la configuración del discurso opositor. Una pastoral colectiva a principios de 1932 señaló qué normas debían guiar la conducta de los católicos ante la legislación sobre enseñanza. El mensaje indicaba, en primer lugar, el carácter injusto del momento, lo que les permitía justificar su intervención en el conflicto:

No se puede, sin violación del derecho natural, impedir a los padres de familia atender a la educación de sus hijos, expresión y prolongación viviente de sí mismos, con la debida libertad de elegir escuela y maestros para ellos, de determinar y controlar la forma educacional en conformidad a sus creencias, deberes, justos designios y legítimas preferencias $(A B C, 01 / 01 / 1932)$.

Descrito el inaceptable panorama, los religiosos deciden exponer su doctrina sobre qué actitud debe caracterizar el comportamiento de los fieles siguiendo la ambivalente postura de respetar el poder constituido pero combatiendo la legislación considerada amenazante:

La Iglesia [...] jamás deja de inculcar el acatamiento y obediencia debidos al poder constituído. [...] Una distinción, empero, habrán de tener presente en su actuación: la importantísima distinción que debe establecerse entre «poder constituído» y «legislación» [...] La aceptación del primero no implica, por tanto, de ningún modo la conformidad, menos aún la obediencia, a la segunda en aquello que esté en oposición con la ley de Dios y de la Iglesia [...] todos los católicos considerarán como un deber religioso y civil desplegar perseverante actividad y usar de toda su influencia para contener los abusos progresivos de la legislación $(A B C, 01 / 01 / 1932)$.

Insistir en las mismas ideas es lo que hizo, al año siguiente, el cardenal de Toledo, Isidro Gomá, en la carta-pastoral que publicó en el mes de julio, pidiendo la resistencia de los católicos ante la Ley de Confesiones y Congregaciones Religiosas ("La mala voluntad, y la mala ley que de ella procede, es lo que debemos rechazar"):

Esta resistencia pasiva a la ley no es ofensa al legislador ni pecado de desobediencia. [...] El que hace injuria a su oficio de legislador es quien promulga una ley injusta. La ley es orden y factor de orden, y la injusticia es esencialmente desorden. 
$\mathrm{Ni}$ es desobediencia no acatar la ley injusta, sino obediencia a un orden y a una ley superior (El Debate, 20/07/1933).

Pero si hubo un colectivo que desempeñó un papel clave en esta reacción fue el encabezado por los padres de familia católicos. Sus esfuerzos siempre se dirigieron a hacer frente a lo que consideraban un ataque: la escuela única que, sería, según denunciaban, el producto de la puesta en marcha de la Ley de Confesiones y Congregaciones Religiosas. Ella representaría el componente de injusticia que debía generar suficiente ira entre quienes compartieran una identidad católica. En un escrito dirigido a la prensa por la Agrupación Defensa y Libertad de los Padres en la Educación de los Hijos se aseguraba, en este sentido, que la ley es "persecutoria" y "anticonstitucional" y que "lleva en sí mismo un germen de muerte y de daños incalculables" (El Debate, 01/06/1933).

Entre otras iniciativas, los padres de familia se entrevistaron con figuras influyentes para, así, intentar modificar el rumbo de los acontecimientos. En febrero de 1933, por ejemplo, visitaron con este objetivo al presidente de la República, Niceto Alcalá-Zamora:

...el Consejo de la Confederación ha querido, recogiendo un evidente estado de opinión, llevar el asunto hasta la más alta representación de los Poderes del Estado, advirtiendo la grave situación que crearía a la aprobación de una ley, que una numerosísima e importante masa de ciudadanos católicos de todas clases sociales, repudiará siempre en el fuero interno de su conciencia, por considerarla injusta pues quebranta convicciones religiosas sincera y honradamente sentidas y afecta a un derecho inalienable, nacido de la propia naturaleza humana, como es el de la paternidad (El Debate, 15/02/1933).

Sobre quién debía actuar y qué debía hacerse frente a la legislación considerada injusta, los máximos representantes de la reacción conservadora tuvieron claro dónde incidir en sus discursos: todos los católicos tenían que unir sus fuerzas. La Confederación emitió un manifiesto dirigido a los padres de familia en mayo de 1933 con el propósito de dar a conocer su postura ante la recién aprobada ley y ofrecer orientación a los progenitores respecto a qué actitud adoptar ante la norma:

Y he aquí que esta opresión sectaria de los que gobiernan se ejerce sobre el sector más numeroso del país.

Ningún país de Europa, fuera de Rusia; ninguno de América, excepto Méjico, ha consumado un tan ingente atropello a los derechos docentes de la Familia y de la Iglesia.

Y la infiere [una profunda ofensa] también a la sociedad y a los padres de familia, conculcando sus derechos educativos, para servir a la masonería internacional.

Contra esta ley [...] alzamos desde hoy, los padres de familia católicos, más que nuestro grito angustiado, nuestro perseverante y firme propósito de combatirla con las armas de la justicia y la ciudadanía. 
Reclamamos de todos los padres de familia católicos la inquebrantable voluntad de huir a toda costa de la escuela laica, y de contribuir, con un noble y generoso esfuerzo, a la creación de escuelas católicas, al sostenimiento de obras postescolares y circunescolares que faciliten la educación cristiana.

$\underline{\text { Reclamamos }}[\ldots]$ para que la ley sea derogada con prontitud $(A B C, 27 / 05 / 1933)$.

En un acto organizado un mes más tarde por la Agrupación Defensa y Libertad de los Padres en la Educación de los Hijos, el abogado Ceballos Botín reproducía el mismo marco de acción colectiva, subrayando el motivo de indignación, identificando a las víctimas y señalando el camino a seguir:

Yo vengo a este acto como católico; creo que en este momento no es lícito hablar de política, nada más que en lo que se refiere a la persecución de la Iglesia, y cuando nuestras convicciones son ultrajadas, no es lícito defenderlas en un partido político determinado, es necesario que todos los católicos, sin distinción de matices, nos unamos con la Iglesia; ella define, y nosotros, a obedecer.

Nos hemos congregado aquí para hacer algo más que oír discursos, hay que tomar una determinación práctica. Tenemos que prometer y juramentarnos que, pase lo que pase, nunca llevaremos a nuestros hijos a la escuela laica.

Es necesario que emprendamos una briosa cruzada por toda España, poniendo nuestra voluntad en la defensa de los derechos de la Iglesia, y pidiendo la derogación de esa ley inicua $(A B C, 27 / 06 / 1933)$.

En ese mismo evento, José María Pemán también pidió a los católicos pasar a la acción y orientar sus pasos en la línea que había marcado el papa:

Frente a esta ley se nos da, desde Roma, una consigna: hemos de combatirla por todos los medios legales que nos conceda la ley y el derecho natural hasta conseguir su derogación (ABC, 27/06/1933).

\section{Conclusiones}

Las voces de las figuras católicas más relevantes en la reacción contra la Ley de Confesiones y Congregaciones Religiosas encontraron múltiples cauces para su difusión (cartas, manifiestos, discursos en las Cortes, mítines, conferencias, alocuciones en reuniones asamblearias, entrevistas) y todas ellas quedaron reflejadas fielmente por la prensa afín. Esa cobertura por parte de los diarios nos permite recuperar los discursos de los líderes políticos, religiosos y organizativos más activos en las protestas que envolvieron la aprobación de la norma que intentó poner fin al ejercicio de la enseñanza por parte de la Iglesia. Su análisis revela que la estrategia propagandística de estos actores integró eficazmente los elementos simbólicos, ideológicos y discursivos que favorecen la movilización de los individuos, mostrando una sintonía y complementariedad entre los diferentes mensajes examinados independientemente 
del contexto (político/eclesial/social) en el que fueron producidos. La lectura facilitada y promocionada era, con algún matiz, siempre la misma: una mirada maniquea que invitaba a contemplar la norma como la muestra más clamorosa de persecución por parte de una minoría enemiga que no tenía otro interés que violar de manera abusiva los derechos de la mayoría católica y que, por lo tanto, todos debían desobedecer hasta lograr su derogación. La gravedad que comunican muchos de los fragmentos expuestos en este trabajo demuestra que el fin persuasivo de este despliegue retórico se fundamentó en la agitación de las pasiones en busca de una movilización que se alimentara de ira e indignación moral.

\section{Bibliografía}

ÁLVAREZ TARDÍO, M. (2009). "La revolución en las conciencias. Política y secularización en el primer bienio, 1931-1933". En CUEVA MERINO, J. de la y MONTERO, F. (eds.) (2009). Laicismo y catolicismo: el conflicto político-religioso en la Segunda República. Alcalá de Henares: Universidad de Alcalá de Henares, p. 47-71.

CRUZ, R. (2006). En el nombre del pueblo: república, rebelión y guerra en la España de 1936. Madrid: Siglo XXI.

GAMSON, W. A. (1984). What's News? A Game Simulation of TV News. New York: The Free Press.

GRANDÍO SEOANE, E. (2008). "Sobre el «apoliticismo». CEDA y Acción Católica: política y religión". En MONTERO, F. (ed.) (2008). La Acción Católica en la II República. Alcalá de Henares: Universidad de Alcalá, p. 89-113.

LÓPEZ VILLAVERDE, Á. L. (2008). El gorro frigio y la mitra frente a frente: construcción y diversidad territorial del conflicto político-religioso en la España republicana. Barcelona: Rubeo.

(2009). "El conflicto católico-republicano «desde abajo», 1931-1936". En CUEVA MERINO, J. de la y MONTERO, F. (eds.) (2009). Laicismo y catolicismo: el conflicto político-religioso en la Segunda República. Alcalá de Henares: Universidad de Alcalá de Henares, p. 389-422.

MEER, Fernando de (1978). La constitución de la II República. Pamplona: EUNSA. MONTERO, F. (2008). "La «nueva» Acción Católica de Ángel Herrera durante la II República”. En MONTERO, F. (ed.) (2008). La Acción Católica en la II República. Alcalá de Henares: Universidad de Alcalá, p. 19-42.

MONTERO, J. R. (1977a). La CEDA: el catolicismo social y político en la II República. Vol. I. Madrid: Ediciones de la Revista de Trabajo. (1977b). La CEDA: el catolicismo social y político en la II República. Vol. II. Madrid: Ediciones de la Revista de Trabajo.

ORDOVÁS, J. M. (1993). Historia de la ACN de P. De la Dictadura a la Segunda República (1923-1936). Navarra: Eunsa.

OSTOLAZA ESNAL, M. (2009). "La «guerra escolar» y la movilización de los católicos en la II República (1931-1936)". En CUEVA MERINO, J. de la y 
MONTERO, F. (eds.) (2009). Laicismo y catolicismo: el conflicto político-religioso en la Segunda República. Alcalá de Henares: Universidad de Alcalá de Henares, p. 321-350.

PÉREZ GALÁN, M. (1988). La enseñanza en la segunda República. Madrid: Mondadori España.

PUELLES BENÍTEZ, M. de (2002). "El modelo educativo de la II República". En PUELLES BENÍTEZ, M. de (2002). Educación e ideología en la España contemporánea. Madrid: Tecnos, p. 262-295.

RAMÍREZ JIMÉNEZ, M. (1969). Los grupos de presión en la segunda República española. Madrid: Tecnos.

SÁNCHEZ SÁNCHEZ, I. (2005). "El pan de los fuertes. La «buena prensa» en España". En CUEVA MERINO, J. de la y LÓPEZ VILLAVERDE, A. L. (eds.) (2005). Clericalismo y asociacionismo católico en España: de la Restauración a la Transición. Cuenca: Ediciones de la Universidad de Castilla-La Mancha, p. 51-105.

VERDOY, A. (2009). "Una República sin religiosos: la Ley de Confesiones y Congregaciones Religiosas". En CUEVA MERINO, J. de la y MONTERO, F. (eds.) (2009). Laicismo y catolicismo: el conflicto político-religioso en la Segunda República. Alcalá de Henares: Universidad de Alcalá de Henares, p. 351-388.

WATANABE, C. (2003). Confesionalidad católica y militancia política: la Asociación Católica Nacional de Propagandistas y la Juventud Católica Española (1923-1936). Madrid: Universidad Nacional de Educación a Distancia.

\section{El autor}

Adolfo Carratalá es Doctor en Periodismo por la Universitat de València, donde ha trabajado como investigador y docente en formación (2008-2012). Su tesis doctoral, en la que analiza el tratamiento mediático conservador sobre la introducción de la asignatura Educación para la Ciudadanía y lo compara con el discurso de la prensa católica de la II República, obtuvo el Premio Lorenzo Gomis 2013 otorgado por la Sociedad Española de Periodística. Ha realizado estancias de investigación en la University of Glasgow (2010) y en el Boston College (2011), publicado una decena de artículos y participado en más de quince congresos internacionales y nacionales. Es miembro del Grupo de Investigación Comunicación, Humor y Sátira (GRICOHUSA). 